\title{
Persistence of Staphylococcus aureus in Penicillin in vitro
}

\author{
By JANET B. GUNNISON, MARGARET A. FRAHER AND E. JAWETZ \\ Department of Microbiology, University of California, San Francisco Medical Center, \\ San Francisco 22, California, U.S.A.
}

(Received 23 December 1963)

\begin{abstract}
SUMMARY
After exposure of Staphylococcus aureus strain Oxford (н) to penicillin in vitro under conditions leading to the death of at least $99.9 \%$ of the exposed population, the offspring of surviving cocci ('persisters') showed the same sensitivity as the original population. Successive exposure of the offspring of persisters did not increase the proportion of survivors nor their resistance. Persisters were not the most resistant cocci in the original population; their offspring showed the same distribution of cocci resistance as the parent culture. The number of survivors, about 1 in 2500 cocci, was proportional to the original number when exposed to penicillin in a small volume (10-20 ml.), but not in a larger volume (40-200 $\mathrm{ml}$.). Inocula of less than 10 staphylococci allowed to multiply to $10^{3} / \mathrm{ml}$. before addition of penicillin yielded persisters. Populations greater than about $2 \times 10^{8} / \mathrm{ml}$. were not acted upon by penicillin, even when the majority of the cocci were only $4 \mathrm{hr}$ old, unless the mixtures were shaken. The proportion of survivors at $37^{\circ}$ from equal volumes of penicillin broth containing $10^{5}-10^{8}$ organisms $/ \mathrm{ml}$. was not affected by the age and growth phase of the exposed bacteria, conditions of previous storage of the inoculum, initial exposure at low temperature, type of container, aeration by shaking, clumping of cocci, a 1000-fold increase in the dose of penicillin, or addition of streptomycin. When removed from penicillin, persisters and their offspring multiplied at the same rate as the parent culture without requiring a recovery period. The persisters were neither spheroplasts nor $L$ forms. Indirect evidence indicates that persisters survived because at the time of first contact with the penicillin they were in a state unfavourable to initiation of division or cell wall synthesis.
\end{abstract}

\section{INTRODUCTION}

In populations of staphylococci exposed to penicillin a few cocci usually survive after $99 \%$ or more have been killed (Hobby, Meyer \& Chaffee, 1942; Rammelkamp \& Keefer, 1943; Rantz \& Kirby, 1944; Chain \& Duthie, 1945). Bigger (1944a, $b)$ found that the offspring of such surviving cocci were as sensitive to penicillin as those of the parent culture and designated these penicillin-sensitive survivors as 'persisters'. Persisting cocci behave as if they are genotypically drug-sensitive but phenotypically drug-resistant (Davis, 1954).

In infection, persisters may be responsible in part for occasional failure of chemotherapeutic agents to eradicate bacteria in spite of apparent in vitro sensitivity and initial satisfactory response of the patient. In such situations, the illness may recur and bacteria isolated at the time of recurrence may appear fully susceptible to the drug used. This ability of drug-susceptible micro-organisms to survive the action of 
a drug in vivo was designated as 'microbial persistence' by McDermott (1958). Survival often involved a state of 'drug-indifference' wherein all or many of the organisms in a given population were neither permanently damaged by a drug nor able to multiply in its presence. The 'persisters' of Bigger, unlike the 'drugindifferent' micro-organisms of McDermott, survive under conditions leading to the death of most of the exposed population.

In the present paper, 'persisters' are defined as those members of a drug-sensitive population of bacteria in pure culture which survive the action of a drug under conditions resulting in the death of at least $99.9 \%$ of the exposed organisms and which produce offspring that are as sensitive as the original culture. Modifications of the in vitro methods of Bigger were selected rather than those involving complex interactions of micro-organisms and infected animals. In a preliminary report, Bigger's findings were partly confirmed (Gunnison \& Jawetz, 1958). It was hoped that a re-investigation of Bigger's observations by more precise quantitative methods interpreted in the light of current knowledge of penicillin action might lead to better understanding of the nature of persisters.

\section{METHODS}

Bacteria. Staphylococcus aureus, strain Oxford (н), $\$ 3$ R 9647, obtained from the Merck Institute for Therapeutic Research, where it had been brought in 1942 by Dr N. G. Heatley, was used. This strain was chosen because it had been tested by Bigger, it does not produce penicillinase, and its sensitivity to penicillin has remained stable (Cowan, 1945; Oeding \& Ostervold, 1959). The stock culture was pretested for sensitivity to penicillin, grown in broth, and stored at $-10^{\circ}$. The term 'parent culture' refers to subcultures of this strain which have not been exposed to penicillin.

Penicillin. Crystalline potassium penicillin G was dissolved in sterile distilled water to 1000 units $/ \mathrm{ml}$. and stored at $-10^{\circ}$ for $1-2$ weeks. Dilutions in broth were prepared just before use. Unless otherwise stated, the test dose was 0.25K unit penicillin $\mathrm{G} / \mathrm{ml}$. (0.15 $\mu \mathrm{g} . / \mathrm{ml}$.), about 2.5 times the minimal bactericidal dose. The amount of penicillin carried over in subcultures of $0.1 \mathrm{ml}$. samples was not bacteriostatic for the test culture.

Media. Tests were made in broth composed of proteose peptone No. 3 (Difco), 20 g.; glucose, 0.5 g.; sodium chloride, 5 g.; disodium phosphate $\left(\mathrm{Na}_{2} \mathrm{HPO}_{4} .12 \mathrm{H}_{2} \mathrm{O}\right)$, 5 g.; water, $1000 \mathrm{ml}$.; pH 7.2. Proteose No. 3 agar (Difco) was used for plate counts.

Procedure. For 'standard' tests, $9 \mathrm{ml}$. portions of broth containing $\mathbf{0 . 2 5}$ unit penicillin $/ \mathrm{ml}$. in $18 \times 150 \mathrm{~mm}$. test tubes with loose-fitting metal caps (Morton) were pre-warmed to $37^{\circ}$ and inoculated with $1 \mathrm{ml}$. of an 18-hr broth culture (about $3 \times 10^{8} \mathrm{cocci} / \mathrm{ml}$.) of Staphylococcus aureus $(\mathrm{H})$ or with serial tenfold dilutions thereof. After thorough mixing, the tubes were incubated at $37^{\circ}$ without further shaking except when samples were removed. Samples $(0.5 \mathrm{ml}$.) were withdrawn at intervals and tenfold dilutions were prepared in sterile distilled water. Plate counts were made by spreading $0.1 \mathrm{ml}$. of sample or dilution with bent glass rods on the surfaces of agar plates, with or without different amounts of penicillin.

Such counts determine the number of clumps or colony-forming 'units' of 
staphylococci rather than of individual cocci, and the number of viable cocci per colony-forming unit might increase or decrease without altering the plate count. Moreover, cocci which survived the action of penicillin might fail to produce colonies (Eagle, 1954). The 'number of cocci $/ \mathrm{ml}$.' refers to the number of colonyforming units; ' $99 \%$ of the population were killed' means that $99 \%$ of the original units no longer formed colonies. Differences of less than 1 log raise were disregarded because of the inherent errors of the method.

In other tests, 18-180 ml. portions of penicillin broth in flasks or bottles with various kinds of closures were pre-warmed to $37^{\circ}$ and inoculated with $2-20 \mathrm{ml}$. of diluted or undiluted culture. Whenever the effects of variations in the conditions of exposure were tested, 10 or 20 replicates of each model system were compared. Penicillinase concentrate (Difco) was added to media when prompt inactivation of penicillin was desired.

Surviving bacteria or their offspring were tested for sensitivity in comparison with the parent culture by inoculating into series of tubes of broth containing penicillin in twofold increments, by direct plating on agar containing graded concentrations of penicillin in increments of 0.005 unit/ml., or by replica plating of colọnies from penicillin-free agar on to penicillin agar. Since survivors might include both resistant organisms and 'persisters', the latter term is used only when the surviving organisms have been shown to be as sensitive as the parent culture.

Assays of residual penicillin were made after incubation for 18-24 hr. Staphylococci were removed by filtration through Seitz filters and the filtrate was assayed by the tube dilution method, with either the parent culture or a highly sensitive strain of Streptococcus pyogenes as the test organism. Uninoculated controls otherwise treated in identical fashion were tested simultaneously.

\section{RESULTS}

In tests by the 'standard' procedure described above, Bigger's finding (1944 $a, b)$ that a small proportion of the exposed population of Staphylococcus aureus (н) survived in the presence of penicillin was confirmed. After $4 \mathrm{hr}$ the viable count had dropped to about $10 \%$ of the original number, after $8 \mathrm{hr}$ to about $1 \%$, and by $18 \mathrm{hr}$ to above $0.1 \%$ or less (Fig. 1). Survivors remained viable for 2-30 days in the presence of penicillin with wide variation in their survival time beyond the first $24 \mathrm{hr}$. The colonies were of the same size and appearance as those of the parent culture. In spite of difficulties inherent in the technique, repeated tests under the same conditions gave fairly uniform results. In a series of 123 tests a mean number of $3.4 \times 10^{7} \pm 0.3 \times 10^{7} / \mathrm{ml}$. exposed for $18 \mathrm{hr}$ yielded a mean of $0.039 \pm 0.02 \%$ survivors at $95 \%$ confidence limits.

These survivors were regarded as 'persisters' because their offspring consistently showed about the same degree of sensitivity as the original population when tested in broth. For both the parent culture and the offspring of persisters the minimal concentration of penicillin which prevented growth in broth for $24 \mathrm{hr}$ of an inoculum of $10^{7} \mathrm{cocci} / \mathrm{ml}$. was $0.04 \mathrm{unit} / \mathrm{ml}$; t the minimal concentration killing $99.9 \%$ within $24 \mathrm{hr}$ was $0 \cdot 1 \mathrm{unit} / \mathrm{ml}$.

Subcultures of persisters when again treated with penicillin $0.25 \mathrm{unit} / \mathrm{ml}$. yielded approximately the same number of survivors as before. In four successive exposures 
there were no significant differences in the proportion of persisters nor in the sensitivity of their offspring as determined by dilution tests in broth.

To define the sensitivities more accurately the numbers of organisms able to produce colonies on closely graded concentrations of penicillin in agar were determined. Enumeration of coccal units able to multiply on given concentrations of penicillin agar may be misleading and can only be used as a guide to the behaviour of a bacterial population (Barber, 1953). A resistant colony might arise from a single coccus in a clump of staphylococci (Eagle, Fleischman \& Levy, 1952). Fine differences in resistance might be obscured by the use of a log scale at the sensitive part of the scale and of too large increments of penicillin (Hughes, 1952), as well as by a probable $10 \%$ error in plate counts. In spite of these difficulties, the method demonstrated gradations in sensitivity which were not detectable in broth tests.

In the parent culture, the distribution of cocci of different penicillin susceptibilities was similar to that reported by Demerec (1945) and by Mayr-Harting (1955). Slight differences in resistance among cocci or clumps of cocci gave a continuous spectrum, with the number able to form colonies decreasing as the concentration of penicillin increased over a narrow range as observed by Eagle et al. (1952). There was no inhibition on plates containing 0.02 unit penicillin $/ \mathrm{ml}$., $90 \%$ inhibition with 0.03 unit $/ \mathrm{ml}$, and complete inhibition with $0.08 \mathrm{unit} / \mathrm{ml}$. From an inoculum of $10^{6}$ organisms, about $0.1 \%$ formed minute colonies in $48-96 \mathrm{hr}$ on plates with 0.045 unit penicillin $/ \mathrm{ml}$; about $0.01 \%$ with $0.05 \mathrm{unit} / \mathrm{ml}$; and about $0.001 \%$ with 0.055 unit $/ \mathrm{ml}$. Suspensions of randomly selected colonies of the parent culture plated directly on penicillin agar showed slight variation in resistance among cocci or clumps of cocci within a given colony as Hughes (1952) had demonstrated with single cocci technique.

Since the proportion of staphylococci growing on low concentrations of penicillin agar was similar to the proportion surviving in higher concentrations of penicillin broth, persisters might represent the most resistant cocci in a given population. However, in randomly chosen colonies of survivors recovered on penicillin-free agar, suspended in broth, and plated on penicillin agar either immediately or after incubation for $18 \mathrm{hr}$ the distribution of resistant cocci was similar to that of the parent culture. Hence, if persisters were the most resistant cocci present at the time of exposure, this resistance was not transmitted uniformly to their offspring.

Staphylococci closely related genetically may have similar resistance to penicillin for several cell divisions (Hughes, 1952). To test whether the more immediate offspring of persisters were any more resistant than those in $\mathbf{1 8} \mathrm{hr}$ colonies, replica plating was used. After overnight exposure in penicillin broth, samples were plated on penicillin-free agar and incubated; at 2,7 and $8 \mathrm{hr}$ replica plates from the penicillin-free agar were made on to graded penicillin concentrations in nutrient agar. Replica plating from the parent culture was done at the same intervals. There were no marked differences in resistance between the earlier and the later offspring of survivors, nor between these and the parent.

To determine whether the most resistant cocci in the parent culture survived in bacterial concentrations of penicillin direct plate counts were made on penicillin $(0.035-0.06 \mathrm{unit} / \mathrm{ml}$.) agar at intervals during incubation in penicillin broth (Fig. 1). Penicillinase could not be added to samples, but immediate control plates from broth with and without penicillin on to penicillin-free and to penicillin agar plates 
showed that diluted portions equivalent to $0.01 \mathrm{ml}$. or less of the original mixture did not contain enough penicillin to influence the initial counts. After $4 \mathrm{hr}$ in penicillin broth, cocci able to form colonies on penicillin agar were rarely detected. Meanwhile, in penicillin-free broth such organisms had increased tenfold. Most of the cocci able to multiply on $0.035-0.06$ unit penicillin $/ \mathrm{ml}$. in agar were apparently killed early in exposure to $\mathbf{0 . 2 5} \mathrm{unit} / \mathrm{ml}$. in broth. Possibly, these slightly resistant cocci remained viable but were unable to form colonies on penicillin agar because of damage during exposure or of inhibition by bound penicillin +that in the agar. However, as far as could be determined, cocci in the parent population able to multiply on low concentrations of penicillin in agar were no more resistant to a bactericidal concentration in broth than the rest of the population (Fig. 1).

Colonies of survivors with maximal resistance were selected from penicillin-free plates by replica plating on to agar containing 0.05-0.06 unit penicillin $/ \mathrm{ml}$. Subcultures of these rare colonies were simultaneously plated directly on to graded concentrations of penicillin in agar and re-exposed to penicillin in broth. On penicillin agar, some of these subcultures behaved like the parent culture; others showed a higher proportion of cocci able to form colonies and may have contained mutants. All yielded about the same number of persisters in broth as did the parent culture. Thus, it is unlikely that persisters merely represent the most resistant of the cocci exposed.

\section{Effect of environmental variables on the frequency of persisters}

Number of staphylococci exposed. In over a hundred tests by the 'standard' procedure in $10 \mathrm{ml}$. volumes, the number of survivors from populations of $10^{5}-10^{7}$ staphylococci $/ \mathrm{ml}$. was roughly proportional to the number present when penicillin was added (Fig. 1; Tables 1, 2). Sometimes the decrease in the number of survivors was less than tenfold when the initial number was decreased from $10^{7}$ to $10^{6} / \mathrm{ml}$. With inocula below $10^{5} \mathrm{cocci} / \mathrm{ml}$. the number of persisters was too small to be detected regularly by plate counts, but they were demonstrable by subculture in broth from inocula as small as $10^{3} \mathrm{cocci} / \mathrm{ml}$. In view of the many variables, the series was analysed by a regression curve. The data fitted a straight line and indicated that the number of persisters was directly related to the number exposed in the range of $10^{5}-10^{8}$ cocci $/ \mathrm{ml}$. in $10-20 \mathrm{ml}$. volumes. When exposed in larger volumes, however, the number of survivors was not related to the original number (see below).

To determine whether potential persisters might emerge from small initial inocula in the absence of penicillin, replicate series in $10 \mathrm{ml}$. volumes of penicillin-free broth were inoculated with numbers of cocci varying from less than 10 to $10^{4} / \mathrm{ml}$. and incubated at $37^{\circ}$. Penicillin was added to different sets of tubes at hourly intervals during multiplication. Provided that the population had reached at least $10^{5}$ cocci/ $\mathrm{ml}$. before the addition of penicillin, the number of persisters at a given population density was approximately the same regardless of the size of the initial inoculum. For example, either 7 cocci $/ \mathrm{ml}$. or $7 \times 10^{4} \mathrm{cocci} / \mathrm{ml}$. if allowed to multiply in $10 \mathrm{ml}$. of penicillin-free broth to about $5 \times 10^{5} \mathrm{cocci} / \mathrm{ml}$. before adding penicillin yielded about 50 persisting cocci $/ \mathrm{ml}$; if allowed to multiply to about $5 \times 10^{7} / \mathrm{ml}$. they yielded about $5 \times 10^{3}$ persisters $/ \mathrm{ml}$. By addition of penicillinase to the original tubes, persisters were detected in cultures arising from less than 10 cocci even when penicillin was added when the population had reached only $10^{3} \mathrm{cocci} / \mathrm{ml}$. 
From populations of about $2 \times 10^{8} \mathrm{cocci} / \mathrm{ml}$. or higher, $15-100 \%$ of the cocci survived (Fig. 1, Table 1). Such large populations are 'indifferent' to penicillin (Chain \& Duthie, 1945; McDermott, 1958), but survivors under such conditions are excluded from the category of persisters as defined here. It was only necessary to

Table 1. The number of persisters of Staphylococcus aureus Oxford strain $(H)$ exposed to penicillin as influenced by the size but not by the age of the population

Organisms exposed to 0.25 unit penicillin $/ \mathrm{ml}$. in broth; total volume $10 \mathrm{ml}$., at $37^{\circ}$ without shaking. $0 \mathrm{hr}$, Initial count immediately after mixing with penicillin broth; $24 \mathrm{hr}$, count after exposure to penicillin for $24 \mathrm{hr}$.

\begin{tabular}{|c|c|c|c|c|}
\hline \multirow{3}{*}{$\begin{array}{l}\text { before ex- } \\
\text { posure to } \\
\text { penicillin } \\
(\mathrm{hr})\end{array}$} & \multicolumn{2}{|c|}{ Penicillin-free agar } & \multicolumn{2}{|c|}{ Penicillin agar (0.05 unit $/ \mathrm{ml}$.) } \\
\hline & $0 \mathrm{hr}$ & $24 \mathrm{hr}$ & $0 \mathrm{hr}$ & $24 \mathrm{hr}$ \\
\hline & \multicolumn{4}{|c|}{ Plate counts (cocci/ml.) } \\
\hline 8 & $9.0 \times 10^{6}$ & $1.0 \times 10^{3}$ & $2.8 \times 10^{3}$ & $<10$ \\
\hline 8 & c. $9.0 \times 10^{5}$ & $1.9 \times 10^{2}$ & $3.0 \times 10^{2}$ & $<10$ \\
\hline 8 & c. $9.0 \times 10^{4}$ & $1.3 \times 10^{1}$ & $3.0 \times 10^{1}$ & $<10$ \\
\hline 18 & $3.0 \times 10^{7}$ & $2.6 \times 10^{3}$ & $2.8 \times 10^{3}$ & $<10$ \\
\hline 18 & $5 \cdot 6 \times 10^{6}$ & $1.7 \times 10^{2}$ & $9.6 \times 10^{2}$ & $<10$ \\
\hline 31 & c. $\mathbf{3 . 0} \times 10^{7}$ & $1.2 \times 10^{3}$ & $2 \cdot 1 \times 10^{3}$ & $<10$ \\
\hline 31 & c. $3.0 \times 10^{6}$ & $1 \cdot 7 \times 10^{2}$ & $1.0 \times 10^{2}$ & $<10$ \\
\hline 31 & c. $3.0 \times 10^{5}$ & $6.0 \times 10^{1}$ & $5 \cdot 0 \times 10^{2}$ & $<10$ \\
\hline \multicolumn{5}{|l|}{$\begin{array}{c}\text { No } \\
\text { penicillin }\end{array}$} \\
\hline 18 & $\mathbf{3 . 0} \times 10^{7}$ & $4.9 \times 10^{8}$ & $1.2 \times 10^{3}$ & $2 \cdot 2 \times 10^{4}$ \\
\hline 18 & c. $3.0 \times 10^{6}$ & $3.8 \times 10^{8}$ & $8.0 \times 10^{2}$ & $7.5 \times 10^{3}$ \\
\hline
\end{tabular}

Table 2. Effect of volume of broth and of size of population of Staphylococcus aureus Oxford strain $(H)$ exposed to penicillin upon the number of survivors

Culture, broth, and 0.25 unit penicillin/ml. mixed in $250 \mathrm{mI}$. flasks in volume of $110 \mathrm{ml}$.; $10 \mathrm{ml}$. transferred from each flask to a test tube immediately, incubated at $37^{\circ}$ without shaking. Figures are mean counts from 10 replicate containers.

\begin{tabular}{|c|c|c|}
\hline \multirow{2}{*}{$\begin{array}{c}\text { Number } \\
\text { organisms/ml. } \\
\text { exposed }\end{array}$} & \multicolumn{2}{|c|}{$\begin{array}{l}\text { Plate counts cocci/ml. on peni- } \\
\text { cillin-free agar after } 24 \mathrm{hr} \text { ex- } \\
\text { posure to penicillin in }\end{array}$} \\
\hline & $100 \mathrm{ml}$. volume & $10 \mathrm{ml}$. volume \\
\hline $\begin{array}{l}4.3 \times 10^{7} \\
6.2 \times 10^{6}\end{array}$ & $1.7 \times 10^{4}$ & $\begin{array}{l}3.1 \times 10^{3} \\
6.6 \times 10^{2}\end{array}$ \\
\hline $\begin{array}{l}6.2 \times 10^{0} \\
9.9 \times 10^{5}\end{array}$ & $1.4 \times 10^{4}$ & $1.2 \times 10^{2}$ \\
\hline $5.3 \times 10^{4}$ & $9 \cdot 4 \times 10^{3}$ & $6.0 \times 10^{1}$ \\
\hline $7.8 \times 10^{8}$ & $1.6 \times 10^{3}$ & $<10$ \\
\hline
\end{tabular}

dilute these large populations tenfold or less, either in fresh broth or in supernatant broth obtained by centrifuging part of the culture, or to remove $10 \%$ of the cocci by centrifugation, to obtain the usual low number of persisters (Table 3). In an attempt to 'divorce' the number of bacteria from their age, young cultures were centrifuged and resuspended in broth to give high concentrations of cocci as had been done by Eagle \& Musselman (1949) and Berntsen (unpublished, quoted by McDermott, 1958) with conflicting results. Cultures 2-7 hr old concentrated to 
$2-5 \times 10^{8} \mathrm{cocci} / \mathrm{ml}$. behaved like equal numbers of $18-31 \mathrm{hr}$ culture cocci with survival rates of $30-50 \%$; those concentrated only to $5 \times 10^{7}-1 \times 10^{8} / \mathrm{ml}$. gave survival rates of 0.01-0.02\% (Table 3). These results, in accord with those of Eagle \& Musselman (1949), were similar whether the cocci were re-suspended in the broth in which they had grown, in a filtrate of a $24 \mathrm{hr}$ culture, or in fresh broth; hence, metabolites in the medium seemed to have no effect. A state of 'indifference' to penicillin seemed to depend upon the concentration of the cocci rather than upon their age.

Table 3. Relative insusceptibility to penicillin of large numbers of organisms of Staphylococcus aureus Oxford strain $(H)$ regardless of age

Organisms were exposed to 0.25 unit penicillin $/ \mathrm{ml}$. in broth; total volume $37^{\circ}$ without shaking. $0 \mathrm{hr}$, Initial count immediately after mixing with penicillin broth; $24 \mathrm{hr}$, count after exposure to penicillin for $24 \mathrm{hr}$.

\begin{tabular}{|c|c|c|c|}
\hline \multirow{2}{*}{$\begin{array}{c}\text { Age of } \\
\text { organisms } \\
\text { (hr) }\end{array}$} & \multicolumn{2}{|c|}{ Plate counts on drug-free agar cocci $/ \mathrm{ml}$. } & \multirow{2}{*}{$\begin{array}{l}\% \text { of population } \\
\text { surviving }\end{array}$} \\
\hline & $\mathbf{O} \mathbf{h r}$ & $24 \mathrm{hr}$ & \\
\hline $4^{*}$ & $6 \times 10^{8}$ & $3 \times 10^{8}$ & $50 \cdot 0$ \\
\hline 4 & $4 \times 10^{7}$ & $2 \times 10^{3}$ & 0.005 \\
\hline 7 & $7 \times 10^{8}$ & $2 \times 10^{8}$ & $28 \cdot 5$ \\
\hline 7 & $2 \times 10^{7}$ & $4 \times 10^{3}$ & 0.02 \\
\hline 18 & $4 \times 10^{8}$ & $6 \times 10^{7}$ & $15 \cdot 00$ \\
\hline 18 & $2 \times 10^{7}$ & $2 \times 10^{3}$ & 0.01 \\
\hline 32 & $8 \times 10^{8}$ & $4 \times 10^{8}$ & $50 \cdot 00$ \\
\hline 32 & $4 \times 10^{7}$ & $8 \times 10^{8}$ & 0.02 \\
\hline \multicolumn{4}{|l|}{$\begin{array}{c}\text { No } \\
\text { penicillin }\end{array}$} \\
\hline 18 & $4 \times 10^{8}$ & $3 \times 10^{8}$ & - \\
\hline 18 & $3 \times 10^{7}$ & $4 \times 10^{8}$ & - \\
\hline
\end{tabular}

\footnotetext{
* Organisms were concentrated by centrifugation in the broth in which they had grown; results were similar when resuspended in fresh broth.
}

Assay of residual penicillin after contact with populations greater than $10^{8}$ cocci/ $\mathrm{ml}$. showed little decrease in its potency. Even after $24 \mathrm{hr}$ at $37^{\circ}$, the concentration of penicillin showed at most a twofold decrease, no greater than that with uninoculated controls and well above the minimal inhibitory concentration. Hence, there was no evidence that the high survival rate was related to more rapid decay of penicillin when heavily inoculated such as Sabath \& Finland (1963) observed with methicillin and other semi-synthetic penicillins.

Rogers (1959) showed that a broth culture of staphylococci at a stable population of $10^{8} \mathrm{cocci} / \mathrm{ml}$. increased to $10^{9} \mathrm{cocci} / \mathrm{ml}$. when shaken vigorously and that penicillin susceptibility reappeared with this new upsurge of growth. We confirmed his findings with both $6 \mathrm{hr}$ and $18 \mathrm{hr}$ cultures containing 3-4 $\times 10^{8} \mathrm{cocci} / \mathrm{ml}$. When these large populations were shaken for $10-30 \mathrm{~min}$. before addition of penicillin and then incubated with continuous shaking for $18 \mathrm{hr}$ only 0.005-0.1\% survived as compared with 15-50\% in unshaken cultures. Penicillin-free controls showed no increase in the number of cocci when not shaken, but a tenfold increase when shaken. These results are consistent with the frequent observation that bacteria are maximally susceptible to penicillin only when able to multiply in the absence of the drug (Hobby et al. 1942). 
Volume of broth. The percentage of survivors was higher when the staphylococci were exposed to penicillin in $40-200 \mathrm{ml}$. of broth preheated to $37^{\circ}$ than in $10-20 \mathrm{ml}$. (Table 2), as had been found by Bigger $(1944 a, b)$. In $30 \mathrm{ml}$. volumes the number of survivors varied from test to test. The number of survivors in $40-200 \mathrm{ml}$. volumes was not proportional to the number exposed, as it was in 10-20 ml. volumes, but fell in a range of about $5 \times 10^{3}-5 \times 10^{4} \mathrm{cocci} / \mathrm{ml}$, regardless of the initial number, provided that this was at least $5 \times 10^{4} / \mathrm{ml}$. and not more than $10^{8} / \mathrm{ml}$. With an inoculum of about $5 \times 10^{7} \mathrm{cocci} / \mathrm{ml}$. the survival rate was slightly higher in the larger volumes than in the smaller, although the differences sometimes fell within the standard error of the plate counts. With inocula of $10^{5} \mathrm{cocci} / \mathrm{ml}$. or less the number of survivors $/ \mathrm{ml}$. was usually at least 100 times greater in $40-100 \mathrm{ml}$. than in 10-20 ml. volumes, so that the organisms behaved as if they were 'indifferent' in the larger volumes.

To obtain comparable initial conditions, several series of mixtures of broth, penicillin, and bacteria were made in 20 replicate containers with a final volume of $110 \mathrm{ml}$; from each of these, $10 \mathrm{ml}$. portions were transferred immediately to separate containers for incubation along with the remaining $100 \mathrm{ml}$. portions. The number of persisters/ml. was consistently higher from the larger portions (Table 2). The effect of the length of time of exposure to penicillin in large volumes was tested by periodically removing $10 \mathrm{ml}$. portions and continuing their incubation in tubes. All portions removed within 1-12 hr showed similar low numbers of persisters $/ \mathrm{ml}$; portions removed at 14-18 $\mathrm{hr}$ yielded higher proportions of persisters, comparable to the count obtained from the remainder in the large original container. Hence, whatever factors may have determined the higher rate of survival in the larger volume, they did not exert their influence upon the bacterial population until after exposure for $12 \mathrm{hr}$.

Dispersion of the inoculum did not account for the higher yield of survivors in larger volumes because it was noted both with equal initial numbers $/ \mathrm{ml}$. and with equal total numbers/container. The volume of medium had no demonstrable effect upon the length of the lag period or the growth rate in penicillin-free controls, nor upon the early death rate during the first $8 \mathrm{hr}$ in presence of penicillin. The rate of deterioration of penicillin was no greater in $100 \mathrm{ml}$. than in $10 \mathrm{ml}$. of broth, whether inoculated or not. The sensitivity of survivors from large and small volumes, as determined by both direct and replica plating on penicillin agar, was about the same; the difference could not be attributed entirely to the presence of a greater number of slightly resistant cocci in the larger volume.

Factors without demonstrable effect. The number of persisters was not significantly altered by the size or shape of the containers, by whether or not the closures were airtight, nor by continuous shaking of populations less than $2 \times 10^{8} \mathrm{cocci} / \mathrm{ml}$. during incubation. Hence the higher number of survivors in 40-200 ml. volumes than in $10-20 \mathrm{ml}$. volumes was not related to the degree of aeration. Holding in penicillin broth at $4^{\circ}$ or about $20^{\circ}$ for 2-24 hr before placing at $37^{\circ}$ had no effect upon the outcome. Bigger (1942) stated that even brief chilling before penicillin began to act resulted in a higher number of persisters; this could not be confirmed by us. With continuous exposure at about $20^{\circ}$, the death rate was slower, but the number of persisters was similar to that at $37^{\circ}$. Previous storage of the bacteria in the absence of penicillin for $85-242$ days at $37^{\circ}$, at room temperature or at $-10^{\circ}$, had no 
influence; nor did 8-12 serial transfers at 2-6 hr intervals in penicillin-free broth at $37^{\circ}$. The age of the organisms and whether they were in the lag, the logarithmic, or the early stationary phase at the time penicillin was added made no demonstrable difference. No correlation was observed between the size of clumps of cocci in a given culture and the proportion of survivors. The concentration of penicillin over a range $0 \cdot 1-100$ units $/ \mathrm{ml}$. and the addition of various concentrations of streptomycin to the mixture were without effect upon the number of persisters.

\section{Multiplication of persisters after removal from penicillin}

Bacteria treated with penicillin under conditions permitting their multiplication in the absence of the drug require a recovery period after inactivation of penicillin before they resume multiplication at their normal rate; when treated under conditions not permitting multiplication, this lag is not shown (Parker \& Marsh, 1946; Eagle \& Musselman, 1949). Hence, determination of whether persisters require a recovery period might indicate whether or not they had been capable of multiplication during exposure to penicillin.

Staphylococcus aureus (B) organisms from 8 and $18 \mathrm{hr}$ cultures were inoculated to a concentration of $10^{7} \mathrm{cocci} / \mathrm{ml}$. into broth containing penicillin $0.25 \mathrm{unit} / \mathrm{ml}$. and incubated for $18 \mathrm{hr}$ at $37^{\circ}$. Then penicillinase was added and plate counts were made at 30-60 min. intervals during further incubation at $37^{\circ}$. The rate of multiplication was compared with that of approximately equal numbers of staphylococci never exposed to penicillin. Although preliminary tests had suggested that persisters showed a longer lag than the parent culture (Gunnison \& Jawetz, 1958), more rigorous controls showed this to be untrue. As one control, cocci never exposed to penicillin were inoculated in small numbers approximately equal to the number of persisters into a sterile filtrate of a mixture treated for $18 \mathrm{hr}$ exactly like the test itself so that it contained metabolic products of bacterial growth, substances liberated by lysis of $\mathbf{9 9 . 9} \%$ of the original culture, penicillinase and inactivated penicillin. The parent staphylococci multiplied in this filtrate at the same rate as an equal number in fresh penicillin-free broth. As a second control, sterile broth containing penicillin was incubated along with each test for $18 \mathrm{hr}$, then penicillinase added, and small numbers of previously unexposed cocci inoculated into the broth. Comparison of the growth rate with that of equal numbers in penicillin-free broth showed that penicillin was completely inactivated within $10 \mathrm{~min}$. or less.

Persisters which had survived for $18 \mathrm{hr}$ in penicillin broth multiplied therein after the penicillin had been inactivated, with no increase in lag and at the same rate as controls inoculated with equal numbers of parent culture (Fig. 2). However, cocci removed from penicillin action by addition of penicillinase after only 30-120 min. before any significant decrease in the viable count showed a lag of 1-2 $\mathrm{hr}$ before resumption of their normal growth rate (Fig. 2). Hence, the population exposed for $2 \mathrm{hr}$ or less behaved as if penicillin had exerted an effect, whereas persisters exposed for $18 \mathrm{hr}$ behaved as if they had not been affected by the penicillin.

In other tests, 10-20 replicate tubes of penicillin broth were set up by the standard method along with an equal number of uninoculated control tubes of penicillin broth. After $24 \mathrm{hr}$ at $37^{\circ}$, penicillinase was added to all tubes, The controls were then inoculated with previously untreated staphylococci in numbers similar to the expected number of persisters. Plate counts were made and the time of appearance 
of turbidity at $37^{\circ}$ was recorded. In three trials, persisters and controls became turbid at about the same time. Bigger $(1944 a, b)$ had noted that staphylococci removed from prolonged penicillin action often multiplied rapidly. If it be accepted that bacteria which do not require a recovery period after penicillin treatment have not been affected by the penicillin (Eagle \& Musselman, 1949), these results suggest that persisters were not in a state of potential cell division during exposure to penicillin.

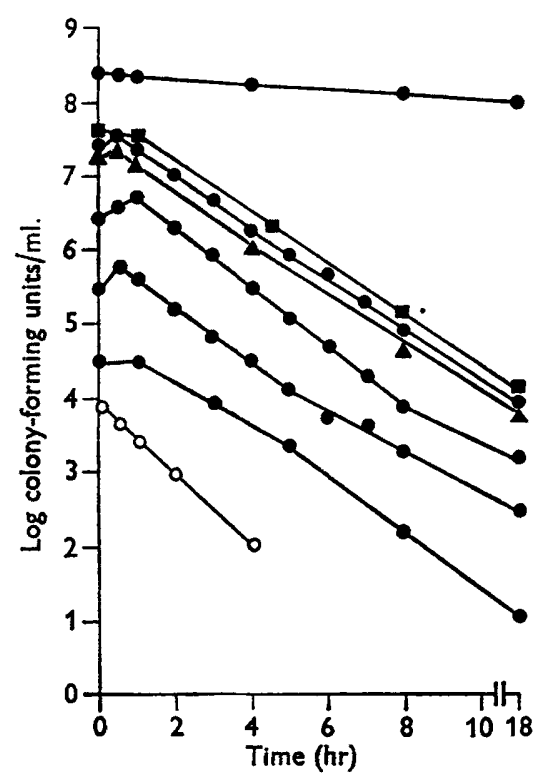

Fig. 1

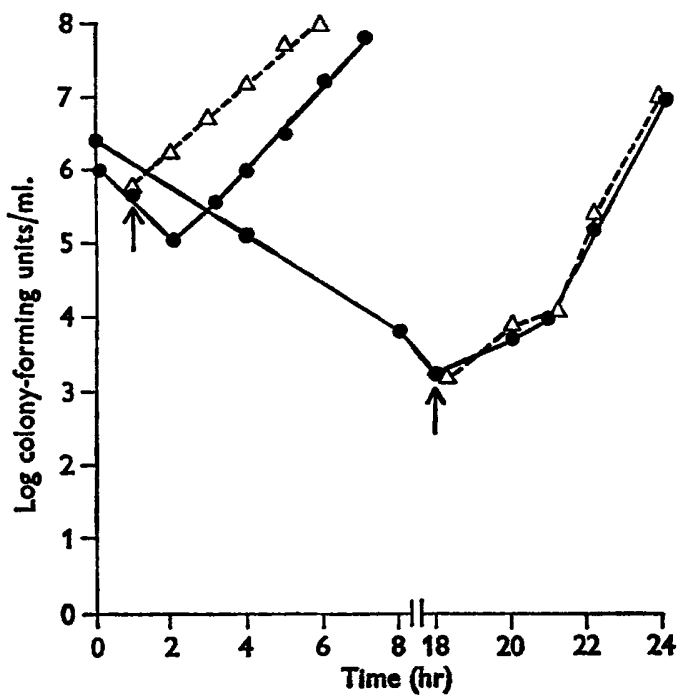

Fig. 2

Fig. 1. Effect of concentration of penicillin and size of exposed population of Staphylococcus aureus Oxford strain (B) upon the number of persisters. Counts made on penicillinfree agar during exposure to 0.1 unit penicillin $/ \mathrm{ml}$., $\Delta-\Delta ; 0.25$ unit $/ \mathrm{ml}$., - - 100 units $/ \mathrm{ml}$., $\quad--$. Counts made on penicillin agar $(0.05 \mathrm{unit} / \mathrm{ml}$.) during exposure of a total initial population of $5 \times 10^{7} \mathrm{cocci} / \mathrm{ml}$. to 0.25 unit penicillin $/ \mathrm{ml}$., $O_{-}-O$. Cocci able to form colonies on penicillin agar were killed within $4 \mathrm{hr}$.

Fig. 2. Rate of growth of Staphylococcus aureus Uxford strain (k) after exposure to $0 \cdot 25$ unit penicillin/ml. in broth at $37^{\circ}$ for $1 \mathrm{hr}$ and for $18 \mathrm{hr}$ upon inactivation of the antibiotic. Penicillinase was added to the mixture at the points indicated by arrows and incubation continued. $\Delta-\cdots \triangle$, Control organisms not exposed to penicillin; $-\cdots$ organisms exposed to penicillin. Organisms treated for 1 hr showed a 2 -hr lag, but those surviving for $18 \mathrm{hr}$ showed no lag.

\section{DISCUSSION}

The persistence of some cocci of genotypically penicillin-sensitive Staphylococcus aureus strain Oxford $(\mathrm{H})$ is readily demonstrated after at least $99.9 \%$ of the population of which they were members have been killed by penicillin, but the reasons for this survival are not clear. Is persistence due to the non-dividing state of the survivors? Penicillin is effective only against bacteria exposed to it under conditions that would permit their multiplication in the absence of penicillin (Hobby et al. 1942; Lee, Foley \& Epstein, 1944; Chain \& Duthie, 1945; Wood \& Smith, 1956). 
Persistence of sensitive bacteria under such conditions has been attributed to the temporary inability of a small proportion of the organisms to divide during the exposure (Bigger, 1944 a , b; Eriksen, 1946; Gunnison \& Jawetz, 1958; McDermott, 1958). Penicillin inhibits synthesis of bacterial cell walls, especially at the division septum, so that bacteria which initiate the division process become osmotically fragile and are killed by lysis unless protected by hypertonic solution (Lederberg, 1957; Park \& Strominger, 1957). With $S$. aureus (в), accumulation of cell wall precursor material coincides with the onset of lysis and a decrease in the number of intact cocci (Ciak \& Hahn, 1962). Dormant or resting bacteria are not susceptible to this action of penicillin on cell wall synthesis and hence survive (Lederberg $\&$ St Clair, 1958).

Are persisters cells which are metabolically 'dormant' at the moment of exposure to penicillin? In experiments reported here there was no difference in generation time nor in rate of multiplication between persister offspring and parent culture after removal from penicillin. This suggests that at the time of initial effective exposure to penicillin the persisters were not susceptible to the biochemical lesion brought about by the penicillin. Cell wall production, and particularly the synthesis and assembly of muramic acid-containing mucopeptide, the presumed 'target' of penicillin action, may be an intermittent process which might lead to temporary insusceptibility of some bacteria in any population.

Does the growth phase of the exposed culture affect the number of survivors? Although the bactericidal rate is a function of the rate at which the majority of the organisms would multiply if no penicillin were present (Hobby \& Dawson, 1944; Lee $e t$ al. 1944) the phase of growth at the time of adding penicillin had little effect upon the number of persisters. It is not surprising that organisms removed directly from storage at $-10^{\circ}$ showed no more persisters than did $18 \mathrm{hr}$ broth cultures, inasmuch as bacteria stored at subfreezing temperatures may initiate multiplication more rapidly when returned to $37^{\circ}$ than unfrozen cells (Hartsell, 1951). Fewer persisters might be expected from cultures in the early log phase than in the stationary phase; but Hamburger \& Carleton (1960) found that staphylococci from 4 or $18 \mathrm{hr}$ cultures might survive in penicillin broth for as long as 9 days.

Do rapidly bactericidal synergistic combinations of penicillin with other antibiotics prevent the emergence of persisters as suggested by Gunnison, Kunishige, Coleman \& Jawetz (1955)? Re-inspection of data and further tests show that small numbers of various bacteria persist even in the presence of synergistic pairs of drugs. With Streptococcus faecalis, for example, although the number of persisters was lower with penicillin + streptomycin than with either compound alone, an appreciable number survived (Gunnison, Jawetz \& Coleman, 1950). Pairs of antibiotics do not act synergistically under conditions which prevent multiplication in drug-free media (Gunnison et al. 1955). Therefore, persistence of organisms when exposed to synergistic pairs under conditions which permit multiplication of most of the organisms in drug-free media favours the assumption that the surviving organisms were unable to initiate division.

Are potential persisters predetermined when penicillin is added to a culture or do they emerge in the presence of the compound? If persisters were present before contact with penicillin, their number under defined conditions might comprise a fixed proportion of the initial number, as it indeed did with Staphylococcus aureus (B) 
in $10 \mathrm{ml}$. volumes of penicillin broth. In modified fluctuation tests, entirely independent cultures showed a greater variance in the number of persisters than did those inoculated from a single culture (Fraher, unpublished 1960). Although such tests are of doubtful validity (Eriksen, 1953), they suggest that persisters do not arise as a result of the presence of penicillin. On the other hand, in volumes of $40 \mathrm{ml}$. or greater the number of survivors was not proportional to the initial number. The results suggest that some factor related to higher survival rates reached a critical value in larger volumes after $12 \mathrm{hr}$ of exposure to penicillin. It is possible that a rarely encountered unknown factor responsible for temporary insusceptibility, perhaps by inducing a pause in cell wall synthesis, may be supplied under these conditions.

Do persisters represent the most resistant cocci in the normal distribution curve shown by a given population? The parent culture of Staphylococcus aureus (ㅍ) contains a few cocci able to form colonies on concentrations of penicillin agar which are inhibitory to the majority of the organism in the population, but subcultures of these colonies may have enhanced, decreased, or unaltered resistance as compared with the original culture (Demerec, 1945; Hughes, 1952). Eagle (1954) found that after 10 serial passages of another strain of Staphylococcid in a concentration of penicillin bacteridal for most of the cocci, the sensitivity of offspring of persisters had not changed. With the $S$. aureus strain Oxford (B) slightly resistant, cocci were among the earliest to be killed. Possibly the somewhat resistant bacteria potentially or actually able to divide may be killed by doses of penicillin in which less resistant cocei survive.

Do persisters differ in any demonstrable way from other bacteria in the same population? Currently there is much interest in the possible survival of spheroplasts or of $\mathbf{L}$ forms in penicillin. The staphylococcal persisters under consideration are definitely not spheroplasts since they are not osmotically fragile but survive suspension in distilled water; nor are they $L$ forms because they produce colonies of normal size within $24 \mathrm{hr}$ on ordinary media when removed from penicillin. They show none of the characteristics of resistant mutants (Rake, McKee, Hamre \& Houck, 1944; Barber, 1953; Mayr-Harting, 1955). Persisters do not differ from the parent culture in size and morphology of colonies, pigment and coagulase production, uniform turbidity in broth, tendency to clump, cellular morphology, or ability to utilize certain carbohydrates. Of course, they may vary in other less obvious and untested properties.

Persisters have been found among various bacteria exposed to many different antibiotics (McDermott, 1958; Hobby \& Lenert, 1957). Streptococcus faecalis, for example, behaved much like Staphylococcus aureus in the presence of penicillin (Mr J. H. Tucker, personal communication). Persisters have been demonstrated in methicillin (Stewart, 1961). They occur upon exposure not only to penicillin and other antibiotics which interfere with cell wall synthesis, but also to those which act by other mechanisms.

In general, bacteria which survive the action of various harmful substances may not transfer this ability to their progeny (Eddy \& Hinshelwood, 1953), After survival in acid, for example, closely related cells share similar resistance for several divisions, but this is not propagated through an overnight subculture (Powell, 1958). In populations treated with various chemicals, heat, or radiation the $10^{3}$ organisms $/ \mathrm{ml}$. 
which usually survive are not the maximally resistant organisms at the extreme of the normal distribution curve. It is difficult to detect resistant organisms among survivors even when they comprise $0.1 \%$ of the original population (Wyss, 1950). Only rarely has heritable resistance of survivors of heat been tested, and this with conflicting results; but available evidence suggests that they are phenotypically deviant rather than genetically resistant (Jordan, Jacobs \& Davies, 1947; Lederberg, 1949). Persisters probably are the result of random phenotypic accidents due to a multiplicity of independent causes. A given bacteriam may be more or less resistant to a lethal agent at different moments in its life, with or without relation to cell division. Bryson \& Szybalski (1955) suggested that bacteria may survive in an unfavourable microenvironment due to temporary changes at the cell level such as clumping, capsule formation, or unusual accumulation of chemical substances; but that their adaptive advantage is not genetic and so transitory as to defy demonstration after subculture.

Bacterial persistence in vivo was reviewed by McDermott (1958) who inferred from clinical observations and experimental evidence that it occurs broadly throughout the microbial world; he speculated that it might be a reflection of a high degree of adaptive plasticity of individual microbes. It seems probable that persisters similar to those studied in vitro do occur in the body and that they may be in part responsible for failures in antibiotic therapy.

We are grateful to Marian C. Shevky, Marjorie L. Hunt and Minetta Sonne for bacteriologic help; and to Calvin Zippin for statistical advice. J. H. Tucker participated in early phases of this work as a United States Public Health Service Medical Student Fellow in 1955. This work was supported in part by grants from the Research Committee of the University of California School of Medicine.

\section{REFERENCES}

Barber, M. (1953). Penicillin-resistant and penicillin-dependent staphylococcal variants. J. gen. Microbiol. 8, 111.

Bigger, J. W. (1944a). The bactericidal action of penicillin on Staphylococcus pyogenes. Irish J. med. Sci. 6, 553, 585.

BigGer, J. W. (1944b). Treatment of staphylococcal infections with penicillin by intermittent sterilization. Lancet, ii, 497.

Bryson, V. \& Szybatski, W. (1955). Microbial drug resistance. Adv. Genet. 7, 1.

Chain, E. \& Duthie, E. S. (1945). Bactericidal and bacteriostatic action of penicillin on the staphylococcus. Lancet, $\mathrm{i}, 652$.

CraK, J. \& HAHN, F. E. (1962). Concurrent morphological and chemical events in Staphylococcus aureus exposed to penicillin. Science, 137, 982.

Cowan, S. T. (1945). The variation in sensitivity to penicillin of strains of the Oxford Staphylococcus H. J. Path. Bact. 57, 145.

DAvis, B. D. (1954). Metabolic factors affecting chemotherapeutic response. In Cellular Metabolism and Infections. N.Y. Acad. Med. Symp. 8, 79.

Demerec, M. (1945). Production of staphylococcus strains resistant to various concentrations of penicillin. Proc. nat. Acad. Sci., Wash. 31, 16.

Eagle, H. (1954). Drug resistance. Ann. N.Y. Acad. Sci. 59, 243.

Fagle, H., Fueischman, R. \& Levy, M. (1952). Development of increased bacterial resistance to antibiotics. I. Continuous resistance to penicillin, chloramphenicol, and streptomycin. J. Bact. 63, 623 . 
Eagle, H. \& Musselman, A. D. (1949). The slow recovery of bacteria from the toxic effects of penicillin. J. Bact. 58, 475.

EDDy, A. A. \& Hinshelwood, C. N. (1953). Death rate of populations of Bact. lactis aerogenes. I. Active adjustment of cells to adverse environments. Proc. roy. Soc. B, $141,118$.

Eriksen, K. R. (1946). Studies on the action of penicillin on some rod-shaped penicillinase producing bacteria. Acta path. microbiol. scand. 23, 489.

ErIksen, K. R. (1953). On the validity of the fluctuation test in studies on the mode of origin of penicillin resistant staphylococci. Acta path. microbiol. scand. 32, 393.

Gunnison, J. B. \& JAwETz, E. (1958). Studies of staphylococcal 'persisters' to penicillin action. Abstr. VII int. Congr. Microbiol., p. 333.

Gunnison, J. B., Jawetz, E. \& Coleman, V. R. (1950). The effect of combinations of antibiotics on enterococci in vitro. J. Lab. clin. Med. 36, 900.

Gunnison, J. B., Kunishige, E., Coleman, V. R. \& Jawetz, E. (1955). The mode of action of antibiotic synergism and antagonism: the effect in vitro on bacteria not actively multiplying. J. gen. Microbiol. 13, 509.

Hamburger, M. \& Carleton, J. (1960). Bactericidal action of penicillin and tetracycline against Gram-positive cocci. Archs. intern. Med. 105, 372.

Hartsell, S. E. (1951). The growth initiation of bacteria in defrosted eggs. Food Res. 16, 97.

Новву, G. L. \& Dawson, M. H. (1944). Effect of rate of growth of bacteria on action of penicillin. Proc. Soc. exp. Biol., N.Y. 56, 181.

HoBBY, G. \& LENERT, T. F. (1957). The in vitro action of antituberculous agents against multiplying and non-multiplying microbial cells. Am. Rev. Tuberc. pulm Dis. 76, 1031.

Hobby, G. L., MeYer, K. \& Chaffee, E. (1942). Observations on the mechanism of action of penicillin. Proc. Soc. exp. Biol., N.Y. 50, 281.

Hughes, W. H. (1952). Variation in penicillin resistance in single-cell cultures of Staphylococcus aureus. J. gen. Microbiol. 6, 175.

Jondan, R. C., Jacobs, S. E. \& Davies, H. E. F. (1947). Studies in the dynamics of disinfection. XI. The effect of lethal temperatures on standard cultures of Bact. coli. IV. An investigation of that portion of the population which survives prolonged exposure at pH 7•0. J. Hyg., Camb. 45, 342.

Lederberg, J. (1949). Bacterial variation. A. Rev. Microbiol. 3, 1.

LEDERBERG, J. (1957). Mechanism of action of penicillin. J. Bact. 73, 144.

Lederberg, J. \& St Clair, J. (1958). Protoplasts and L-type growth of Escherichia coli. J. Bact. 75, 143.

Lee, S. W., Foley, E. J. \& Epstein, J. A. (1944). Mode of action of penicillin; bacterial growth and penicillin activity-Staphylococcus aureus FDA. J. Bact. 48, 393.

Mayr-Harting, A. (1955). The acquisition of penicillin resistance by Staphylococcus aureus, strain Oxford. J. gen. Microbiol. 13, 9.

MCDermotт, W. (1958). Microbial persistence. Yale J. Biol. Med. 30, 257.

Oeding, P. \& Ostervold, B. (1959). The stability of Oxford Staphylococcus $\mathrm{H}$ and other penicillin reference strains. Acta path. microbiol. scand. 46, 149.

Park, J. T. \& Strominger, J. L. (1957). Mode of action of penicillin. Science, 125, 99.

Parker, R. F. \& Marsh, H. C. (1946). The action of penicillin on staphylococcus. J. Bact. 51, 181.

Power., E. O. J. (1958). An outline of the pattern of bacterial generation times. J. gen. Microbiol. 18, 382.

Rake, G., McKee, C. M., Hamre, D. M. \& Houck, C. L. (1944). Studies on penicillin; observations on therapeutic activity and toxicity. J. Immunol. 48, 271.

Rammelzamp, C. H. \& Keefer, C. S. (1943). Penicillin: Its antibacterial effect in whole blood and serum for the hemolytic streptococcus and Staphylococcus aureus. J. clin. Invest. 22, 649.

Rantz, L. A. \& KIrby, W. M. M. (1944). Action of penicillin on staphylococcus in vitro. J. Immunol. 48, 335.

Rogers, D. (1959). Observations on the nature of staphylococcal infections. Bull. N.Y. Acad. Med. 35, 25. 
Sabath, L. D. \& Finland, M. (1963). Inactivation of methicillin, oxacillin, and ancillin by Staphylococcus aureus. Proc. Soc. exp. Biol., N.Y. 111, 547.

STEwarT, G. T. (1960). Microbiological studies on sodium 6 (2,6 dimethoxybenzamido) penicillinate monohydrate (BRL 1241) in vitro and in patients. Br. med. J. i, 694.

Woon, W. B. \& Smith, M. R. (1956). An experimental analysis of the curative action of penicillin in acute bacterial infections. I. The relationship of bacterial growth rates to the antimicrobial effect of penicillin. J. exp. Med. 103, 487 .

Wyss, O. (1950). Bacterial resistance. Ann. N.Y. Acad. Sci. 53, 183. 